\title{
Leprosy among children under 15 years of age: literature review*
}

\author{
Marcela Bahia Barretto de Oliveira ${ }^{1}$
}

Lucia Martins Diniz ${ }^{1}$

DOI: http:/ / dx.doi.org/10.1590/abd1806-4841.20163661

\begin{abstract}
Leprosy is a chronic infectious disease caused by Mycobacterium leprae, representing a public health issue in some countries. Though more prevalent in adults, the detection of new cases in children under 15 years of age reveals an active circulation of bacillus, continued transmission and lack of disease control by the health system, as well as aiding in the monitoring of the endemic. Among patients under 15 years of age, the most affected age group is children between 10 and 14 years of age, although cases of patients of younger than 1 year of age have also been reported. Household contacts are the primary source of infection, given that caretakers, such as babysitters and others, must be considered in this scenario. Paucibacillary forms of the disease prevailed, especially borderline-tuberculoid leprosy, with a single lesion in exposed areas of the body representing the main clinical manifestation. Reactional states: Lepra reactions are rare, although some authors have reported high frequencies of this phenomenon, the most frequent of which is Type 1 Lepra Reaction. Peripheral nerve involvement has been described at alarming rates in some studies, which increases the chance of deformities, a serious problem, especially if one considers the age of these patients. The protective effect of BCG vaccination was found in some studies, but no consensus has been reached among different authors. Children must receive the same multidrug therapy regimen and the doses should, ideally, be calculated based on the child's weight. Adverse reactions to this therapy are rare within this age group. This article aims to review epidemiological, clinical, and therapeutic aspects of leprosy in patients under 15 years of age.
\end{abstract}

Keywords: Child; Epidemiology; Leprosy; Minors

\section{INTRODUCTION}

Leprosy is an infectious disease caused by $\mathrm{My}$ cobacterium leprae, which today represents a severe public health issue. ${ }^{1,2}$ In 2011, three countries made up $83 \%$ of the new cases detected worldwide, with India responsible for $58 \%$ of the cases, Brazil for $16 \%$, and Indonesia for $9 \% .^{3}$

Leprosy is most common in adults; however, the outbreak of cases in children and adolescents shows the active circulation of bacillus, with its continued transmission and the failure of the health system to control this disease. ${ }^{4,5}$ In countries in which leprosy can be considered endemic, such as Brazil, despite the drop in prevalence and incidence rates, the high detection rate of cases in children of under 15 years of age helps to monitor the endemic. ${ }^{6}$

Knowledge of the behavior of leprosy in children under 15 years of age is necessary to recall that this disease can occur in this age group and should fig- ure within differential diagnoses, not only among the hypotheses formulated by the dermatologist, but in all diagnoses from professionals involved in providing medical care to children and adolescents. The early diagnosis of leprosy is essential in the prevention of deformities, whose repercussions are still more catastrophic when treating children under 15 years of age. ${ }^{7}$

\section{EPIDEMIOLOGY}

At the end of 2011, Brazil presented 33,735 new cases of leprosy, with a general detection coefficient of 17.39 cases per every 100,000 inhabitants, which is considered to be an extremely high endemicity. As regards children of under 15 years of age, 2,287 new cases of leprosy have been reported, representing $6.7 \%$ of the total number of cases reported throughout the country, with a detection coefficient of 4.89 cases per 100,000 inhabitants, reflecting an average endemicity index. ${ }^{8}$ 
The incidence rate for leprosy in children under 15 years of age presents a wide variation according to the region of the country. The highest rate found was in the North, with 11.91 cases per 100,000 inhabitants, followed by the Northeast (8.12), Mid-West (7.25), Southeast (1.35), and South (0.33), all per 100,000 inhabitants. ${ }^{8}$

The age group that is most commonly affected by the disease among children under 15 years of age can be found between 10 and 14 years of age, which can be justified by the disease's long incubation period of approximately three to five years. ${ }^{9}$ This fact was illustrated in studies conducted by: Selvasekar et al., who found $58.9 \%$ (468/794); Jain et al., 50\% (306/612); Kar and Job, 69.4\% (191/275); Imbiriba et al., 64.7\% (307/474); Rao, 50\% (16/32); Sachdeva et al., $47.9 \%$ (105/219); Singal et al., 70.3\% (121/172); Chaitra and Bhat, 75\% (27/36); and Lana et al., 80\% $(112 / 140)$. Nevertheless, Santos et al. identified a discrete predominance in the 5 to 9 -year-old age group, in $54.54 \%(42 / 77)$, with the next most affected age group being 10 to 14 -year-olds, $44.15 \%$ (34/77), ${ }^{5,10-18}$

However, cases in patients of less than one year of age have also been reported. Brubaker, Meyers, and Bourland published two cases of 6-month-old children with leprosy confirmed through a histopthological study of a cutaneous lesion. The literature review from these authors revealed a case published in 1914 of a two and a half-month-old child, whose parents had multibacillary leprosy and found, up to 1985, 51 cases of leprosy in children of under one year of age, which were diagnosed through clinical data, histopathological findings of the lesions, or evaluations by specialists in leprosy. The authors speculated on the possibility of vertical/transplacental transmission or through breastfeeding. ${ }^{19}$ As of this year, no cases have been described in children at such a young age, which may well be due to the institution of a multidrug therapy regimen in the world since 1982, adopted even during pregnancy, interrupting a possible vertical transmission.

As regards gender, according to the Brazilian Health Ministry, children under 15 years of age are equally distributed, with 1.163 cases in boys and 1,123 cases in girls in 2012. ${ }^{8}$ This fact was also observed in some studies, such as Selvasekar's, who reported 1.25 boys per each girl (425 boys/369 girls); Hammond and Rao, 1:1 (23/23); Kar and Job, 1.45:1 (163/112); and Imbiriba, 1:1 (238/236). However, a predominance of boys were observed in the findings from Rao, 2.5 boys per each girl (23 boys / 9 girls); Sachedeva, 3.2:1 (167/52); and Singal, 2.3:1 (120/52). ${ }^{10,12-16,20}$

\section{TRANSMISSION}

The main transmission and acquisition path- ways for leprosy are the upper airways, given that multibacillary patients are the largest source of the elimination of bacillus. ${ }^{1}$ It is accepted that household contacts with patients with leprosy are the most prone to catching the disease. ${ }^{11}$ The Brazilian Health Ministry defines as 'household contact' any and every person who lives or has lived with a leprosy patient within the past five years. ${ }^{21}$ Nevertheless, Souza et al. emphasized the importance of also including, in the case of patients under 15 years of age, possible caretakers, who do not necessarily live in the same house. ${ }^{6}$ Romero-Montoya et al., in a study with 12 children in Colombia, found a history of household contact with leprosy patients in nine cases. ${ }^{22}$

According to Van Beers, the risk of a person developing leprosy is nine times greater among household contacts and up to four times greater among contacts with neighbors. ${ }^{23}$ Durães et al. demonstrated a risk of illness of 2.4 times greater than the case index in household contacts as compared to household perimeter contacts, and 2.05 if the contacts were first degree relatives. Considering the same type of household contact, the higher incidence among blood relatives within a nuclear family, as compared to the other blood relatives, demonstrates the component of genetic predisposition, which has been widely reported in prior literature. ${ }^{24}$ Romero-Montoya et al. also reported that the children appear to be more prone to illness than other family members. ${ }^{22}$

One peculiarity of leprosy is that the majority of the people (about 90\%) do not become ill due to one's own natural defense against Mycobaterium leprae, which is related to genetic influences. ${ }^{1}$ The genes involved are still not fully known; however, it is well accepted that both genes from the human leukocyte antigen (HLA) and the non-HLA are involved in one's predisposition to this disease..$^{25}$ The development of the disease has already been associated with the genes that control the macrophage response to bacillus, such as variations in the PRAK2 and PARCRG genes. ${ }^{26}$ More recently, Zhang et al, in a study using a genome scan of a Chinese population, identified variations in seven genes (CCDC122, C13orf31, NOD2, TNFSF15, HLADR, RIPK2, and LRRK2) associated with predisposition to leprosy. ${ }^{27}$

\section{CLINICAL MANIFESTATIONS OF LEPROSY}

Leprosy was first classified by Rabello, who detected the disease in its initial form, known as indeterminate leprosy, and established the characteristic of polarity of the disease, where the patient in the early stages of leprosy, if not treated, would evolve into the tuberculoid (TT) or the lepromatous (LL) forms of leprosy. ${ }^{28}$ In 1953, at the International Congress on Leprosy, held in Madrid, Rabello's classification was main- 
tained but incremented with the definition of unstable forms, called borderline. ${ }^{29}$ In 1966, Ridley and Joplin introduced a classification with a clinical, bacilloscopic, and histopathological basis, and divided the borderline form into borderline-tuberculoid (BT), borderline-borderline (BB), and borderline-lepromatous (BL), while still maintaining the other forms. ${ }^{30}$ In 1982, the World Health Organization, by means of an operational classification, divided the disease into cases - paucibacillary and multibacillary - with the aim of facilitating the diagnosis and treatment in cases of more difficult access to specialized doctors. More recently, studies have adopted the definition of clinical cases according to the number of lesions: up to five cutaneous lesions, paucibacillary, and above five lesions, multibacillary. ${ }^{21}$

In its early stages, leprosy compromises the nerve endings and can consequently affect the nerve trunks. In skin lesions, the M. leprae invades both the sensory fibers and the autonomic fibers, with a consequent reduction in cutaneous sensibility (thermal, pain, and tactile), change in the histamine test, and reduction or absence of excessive sweating. ${ }^{1}$

Indeterminate leprosy is characterized by spots, generally hypochromic, sometimes erythematous, of unclear outer limits, diverse sizes, with change in the thermal and/or pain sensitivity, reduction or absence of hair (alopecia), and reduction or absence of excessive sweating (hypo or anhydrous). It is normally represented a single lesion but can reach up to five lesions and particularly affect the exposed areas of the body. No compromise of the peripheral nerve occurs. Leprosy can last between two and five years, evolving into spontaneous healing or into a disease in one of its polar forms (TT or LL). Through a skin-smear bacilloscopy, no bacillus can be identified and the histopathology of the lesion reveals a discrete chronic inflammation with the predominance of lymphocytes in the perineural, intraneural, and periadnexal areas, especially in the sweat glands, and few undifferentiated histiocytes. ${ }^{1,2}$

TT leprosy is a form of greater resistance to Mycobacterium leprae, with a predominance of the Th1 cellular immune response, thus allowing the confinement of the bacillus and the manifestation of few $\mathrm{cu}$ taneous lesions, generally single lesions. TT leprosy is characterized by a lesion in a fully infiltrated plaque or of erythematous-papular sharp borders, which are externally defined, with change in the thermal, pain, and tactile sensitivity (in this order), hypo or anhydrous areas, and alopecia. This condition also affects exposed areas of the body, and the study of the bacillus in the skin smear is negative. ${ }^{1,2}$ The nerve trunks are often compromised asymetrically. ${ }^{21}$ In the histopathology, from the papillary dermis to the deep dermis, one can observe the formation of TT granulomas full of T CD4 $4^{+}$lymphocytes, epithelial macrophages, mul- tinucleated gigantic cells, and, surrounding this, a few $\mathrm{T} \mathrm{CD} 8^{+}$lymphocytes responsible for the confinement and, at times, the elimination of bacillus. ${ }^{31,32}$

A different presentation of TT leprosy is denominated as nodular leprosy of childhood, which was first described by Lara and De Vera in 1935, and which appears as an erythematous-violaceous nodule on the face or upper limbs of infants. ${ }^{33}$ Some authors also consider the papulonodular, annular, lichenoid lesions or infiltrated plaques as variants of this form, as well as lesions present on the dorsum or other uncovered areas. This occurs in children who have been exposed to an environment with a large quantity of bacillus, primarily mothers with bacilliferous leprosy. ${ }^{34}$ Though it tends to heal spontaneously, this form must be treated. ${ }^{1}$

The LL form initially appears as hypochromic, diffuse, symmetric spots that gradually undergo the infiltration of bacillus-rich macrophages, clinically leading to the manifestation of erythematous or erythematous-brownish lesions, infiltrated, shiny, coalescent, poorly defined lesions of symmetrical distribution. Brownish papules can be seen isolated and full of bacillus, called leproma, in any region of the tegument; infiltration of the face, loss of the external third of the eyebrow (madarosis); and the infiltration of the earlobes (Figure 1). Following the tropism of the bacillus through cold areas of the body and the involvement of skin nerve endings, there is a drying of the skin of the body extremeties in a symmetrical and bilateral manner. The involvement of sensitivity is first thermal, fol-

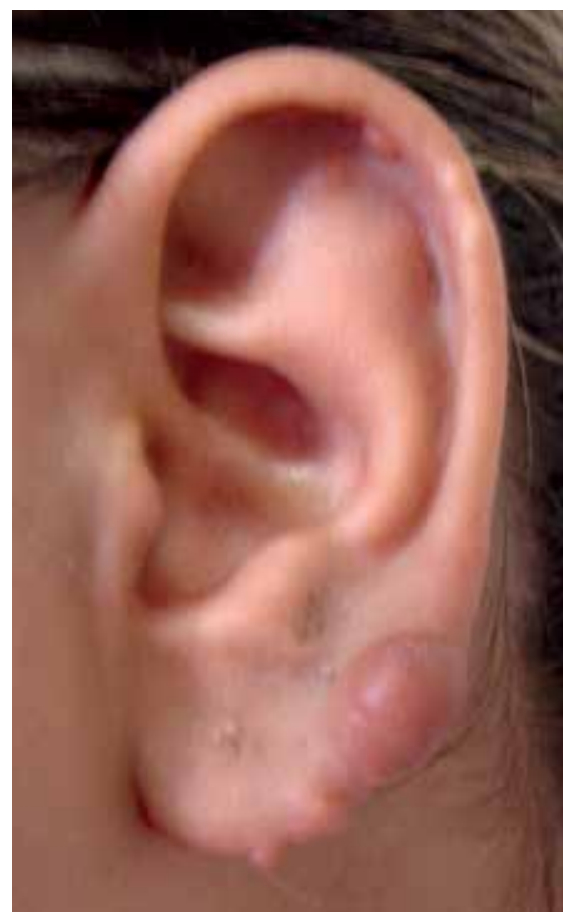

Figure 1:

Earlobe Infiltration and leproma in a 15-year-old patient 
lowed by pain and tactile sensitivity. These are shaped by alopecia, hypo, and anhydrous areas. It is a systemic disease involving internal organs, such as the larynx, pharynx, liver, spleen, suprarenal glands, lymphnodes, etc., due to the lack of cellular immune response to the spreading of bacillus and, consequently, compensation with the Th2 humoral response, which is full of antibodies yet inefficient to contain the Mycobacterium leprae, as it deals with the mandatory intracellular bacillus. ${ }^{1,2}$ The bacillus study through a skin smear proved to be positive with healthy bacillus, and the histopathology of the cutaneous lesion reveals an extensive cell infiltration, which is compact and thick, molded by macrophages with cytoplasm loaded by the bacillus and globs, with large quantities of lumpy lipids, producing the aspect of foam cells (Virchow cells) and, at times, multinucleated, separated from the epidermis by collagenous fiber bands (Unna band), with a scarcity of lymphocytes and surrounding plasmocytes. ${ }^{32}$

Borderline leprosy is an interpolar form, as it presents clinical bacilloscopic and histopathological characteristics, whether tending toward the TT pole (borderline TT), whether toward to the LL (borderline-borderline or borderline-LL), believing that this dichotomy is the product of immunological instability (Figure 2). ${ }^{35}$ There are normally more than five cutaneous lesions. ${ }^{21}$

All of the above classifications are also used to establish the clinical forms in children and adolescents. However, in this age group, the studies show a predominance of the paucibacillary forms, especially the borderline-TT form, which is clinically similar to the TT form, but the outer border of the lesion is not as well defined. ${ }^{1,2,10,13-15,36,37}$

It is important to emphasize that the articles

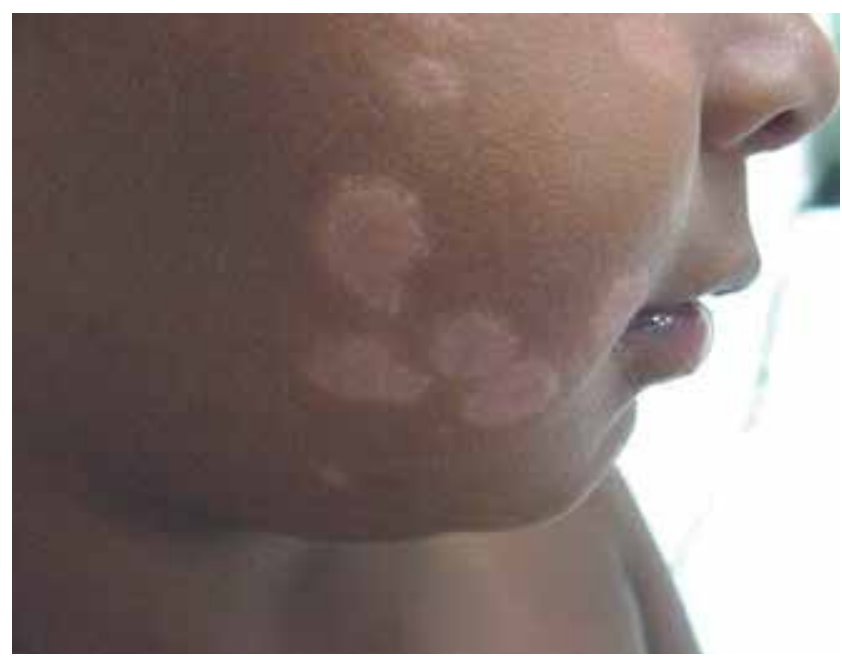

Figure 2: Borderline borderline leprosy in a 3-year-old patient published about leprosy in patients under 15 years of age are not homogeneous as regards the classification used, sometimes using the WHO's operational classification, sometimes using the Ridley and Jopling classification. ${ }^{21,30}$ The absence of standardization in the article for publication make it rather difficult to compile data. Another important point is that, due to the decentralization of the diagnosis and treatment of leprosy in Brazil, it has become impossible to formulate a plausible division, which has been repeated in the studies, as they have treated retrospective studies that reflect the medical care provided by unspecialized doctors.

As regards the number of lesions, most studies on children and adolescents show a predominance of a single lesion ${ }^{10,11,16}$ and in exposed areas. ${ }^{4,10,11,14,16}$ However, Ganapati et al. found 8.8\% (84/346) of the lesions in the gluteal region, highlighting the importance of the full body skin exam. ${ }^{38}$

It is important to remember the existence of musculoskeletal manifestations, such as arthralgia, arthritis, and myalgia, also placing leprosy within the differential diagnoses of juvenile idiopathic arthritis, systemic lupus erythematosus, among other autoimmune diseases. Neder et al. reported a main finding of $14 \%$ of the examined children with musculoskeletal manifestations with asymmetric polyarthritis of the small articulations of the hands. ${ }^{39}$

\section{LEPROSY REACTIONS}

Leprosy reactions are acute/subacute inflammatory processes, mediated by immune cells or by antibodies, present in the evolution of leprosy. ${ }^{2}$ These can be unleashed by infections (dental, urinary, etc.), parasite infestations, vaccinations, physical and emotional stress, among others. These are subdivided into type 1 reaction, which is mediated by the cellular immune response, and type 2 reaction, determined by immune complexes and immune cell cytokines. ${ }^{1}$

The type 1 reaction most commonly occurs in the $\mathrm{BT}, \mathrm{BB}$, and $\mathrm{BL}$ forms. This is characterized by erythema and swelling in the pre-existing lesions and the manifestation of new lesions (papules and plaques) (Figure 3). This can evolve though outbreaks, any one of which can last for four to six months. The more severe reactions can be followed by fever, malaise, anorexia, swelling of the face and body extremities, and neurites. These may be the only appearance of a reaction, called an isolated neurite, whose manifestation is characterized by spontaneous pain or the compression of the peripheral nerve trunk, followed or not by neural thickening and by the involvement of the neurological function (sensory, motor, and autonomic). ${ }^{40}$

The most common clinical presentation of type 2 reaction is the erythema nodosum, which is most commonly found in BL and LL, characterized by the 


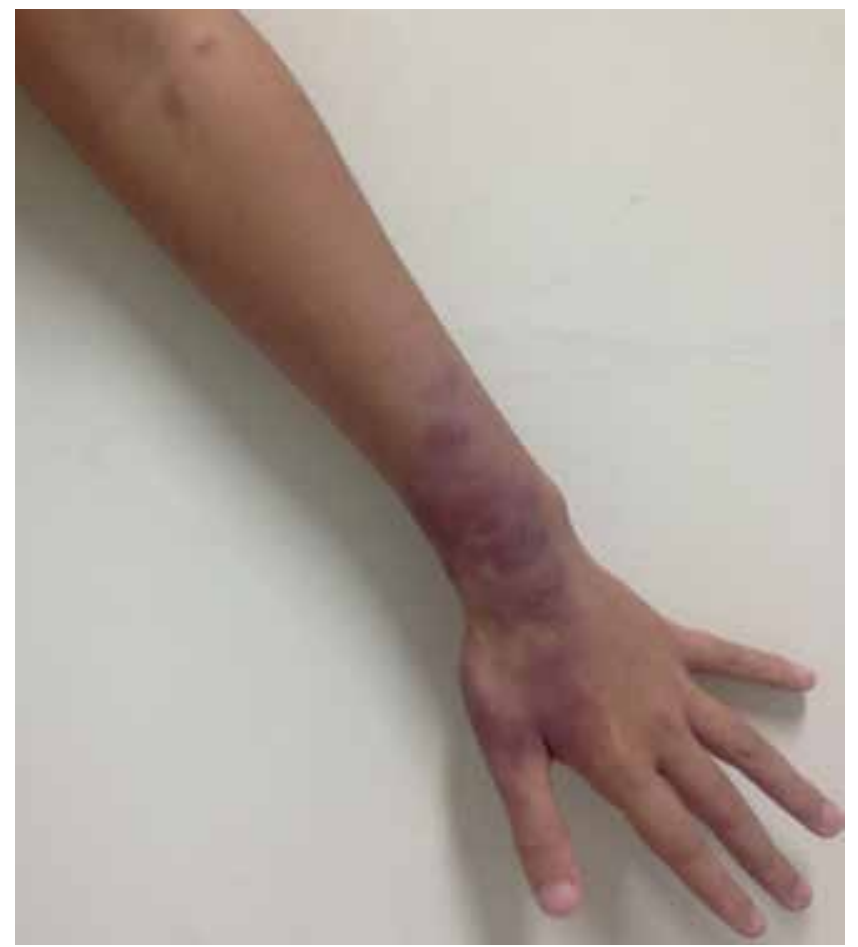

Figure 3: Type 1 lepra reaction in an 8-year-old patient

sudden manifestation of nodules and erythematous, deep, painful, shiny papules, which can remain for 15 to 20 days in the face, upper limbs, lower limbs, and trunk, normally accompanied by fever, malaise, myalgia, arthralgia, iritis, lymphadenopathy, swelling and pain in the hands and feet, neurites (sometimes the only manifestation), among others. This medical condition occurs in episodes or it can be continuous. ${ }^{41}$

Generally, children of under 15 years of age do not present lepra reactions. ${ }^{20,22}$ Some studies have shown a low frequency of lepra reactions, varying between $1.36 \%$ and $8.33 \% .5,10,14,15,42$ Nevertheless, some authors have found a greater occurrence than expected, with rates varying from $18 \%$ to $29.7 \% 11,12,16,20,22,39,43 \mathrm{In}$ all of these studies, the type 1 reaction was the most commonly found, which is expected, given that the most frequent clinical form was borderline BT.

Lepra reactions are the main causes of neural damage and deformities. ${ }^{40}$ Jain et al. found the involvement of peripheral nerves in 186 patients of a total of 306 evaluated children, with more than one thickened nerve in most cases, the ulnar nerve being the most affected. ${ }^{11}$ In 2009, Rao reported neural thickening in multiple nerves in $59.38 \%$ of the cases, which also showed a predominance of ulnar nerve involvement. ${ }^{14}$ Findings from Singal et al. showed $70 \%$ of the patients with thickening, nearly half of whcih presented multiple thickened nerves, predominately in the ulnar nerve. ${ }^{16}$

According to Kar and Job, children with neu- ral thickening have 6.1 times more chances to develop deformities as compared to those without neural widening. These authors, upon studying 275 children under 15 years of age, found a $10.5 \%$ incidence of deformities, with the following risk factors: late diagnosis, multiple cutaneous lesions, multibacillary disease, positive bascilloscopy, various affected nerves, and reactional state at the time of the diagnosis. ${ }^{12}$ The same risk factors were cited by Singal et al. after having evaluated 172 children under 15 years of age and having found a $12.8 \%$ incidence of deformities in the hands, feet, and eyes. ${ }^{16}$

\section{DIAGNOSIS}

The diagnosis of leprosy is essentially clinical, but it can be complemented by the skin smear bacilloscopy and biopsy with a histopathological study of the cutaneous lesion, due to the difficulty in conducting the thermal sensitivity test, primarily in children under 10 years of age, and the need for differential diagnoses with other dermatoses commonly found in childhood. ${ }^{14}$ The younger the child, the more difficult the evaluation of sensitivity. ${ }^{22}$

The Brazilian Health Ministry recommends that a skin smear bacilloscopy be performed in the following situations: in the case of doubt in the operational classification for the administration of a multidrug therapy regimen, differential diagnosis of other dermato-neurological diseases, and cases in which recurrence is suspected. ${ }^{44}$ As this is a painful exam, it is wisest to conduct this exam as of 10 years of age, since a biopsy, together with a histopathological study of the cutaneous lesions, seems to the more appropriate choice.

The finding of positive bacilloscopy is rare in children, having been reported in $10 \%$ of children under 15 years of age.,10,11,12 However, Imbiriba et al. ${ }^{13}$ found positive bacilloscopy in $18.3 \%$ (71/387) of children under 15 years of age who were submitted to the exam, while $\mathrm{Rao}^{14}$ found $25 \%(8 / 32)$ of positive bacilloscopy, and Singal ${ }^{16}, 19.8 \%$ (34/172), given that in 17 children, the bacilloscipy index was greater or equal to four.

The histopathological outcome of the leprosy lesion depends on the appropriate choice of the location where the biopsy is to be performed, as well as of a representative skin sample (including deep skin/hypodermis in the material), and of the experience of the pathologist in dealing with leprosy. ${ }^{14,16}$ Cumari et al. ${ }^{45}$ found a clinical-histopathological correlation of $60.6 \%$, Singal et al. ${ }^{16}$ of $86.1 \%$, and Chaitra and Bhat ${ }^{5}$ of $85.16 \%$.

Currently, studies have been conducted using the ML-FLOW test (anti-PGL-I) to evaluate the seroprevalence of household and school contacts in hyperendemic areas. ${ }^{46}$ Barreto et al. conducted a study with school children from eight hyperendemic towns in the 
Amazon region and found 63 (4\%) of the school children under an average age of 13 years and 3 months diagnosed with leprosy. In addition, 777 (48.8\%) of the 1,592 school children proved to be seropositive for anti-PGL-I. This seroprevalence was significantly higher among girls from rural areas and public school children, suggesting the possibility of undiagnosed cases and subclinical infections among children in the Amazon region. The importance of the study on these school children in hyperendemic areas was the early diagnosis of the disease, in turn avoiding disabilities and deformities, preventing infection in the community, and blocking the transmission chain. ${ }^{47}$

More recently, Barreto et al., in a temporal and spatial analysis of leprosy cases in a hyperendemic region showed a relationship between the high titers of anti-PGL1 in children and the clusters of the disease. These findings can be used in the expansion of interventions in high-risk areas. ${ }^{9}$

\section{BCG VACCINATION}

The Brazilian Health Ministry recommends the application of two doses of the BCG vaccine to all household contact of the cases of leprosy, regardless of whether it is paucibacillary or multibacillary, with a six month gap between the first and second doses. ${ }^{21}$

The protector effect of the BCG vaccine against leprosy showed a protection varying from $20 \%$ to $80 \%$ in Brazilian studies and in other countries, but more generally protecting the population against multibacillary forms. Sundaresan et al. reported the protector effect of BCG after 14 years of application, finding a $20 \%$ protection rate, with a variation concerning the age of application, gender, and contact with leprosy. The authors compared one assay in Uganda, which showed an $81 \%$ protection rate with four years of follow-up; an assay in New Guinea, which presented a
$46 \%$ protection rate after 9 years; and in India, which presented a $23 \%$ protection rate after 10 years. ${ }^{48}$

In a meta-analysis, the protector rate of revaccination with BCG was reported in seven experimental studies and nineteen observational studies. The protection varied between $26 \%$ and $61 \%$, respectively. This procedure proved to be more effective regarding the development of multibacillary forms. Although the effect diminished with age, no variation was observed in the BCG action in relation to the age upon application of the first dose of the vaccine, but the reinforcement increased its response and should be encouraged in household contacts with multibacillary patients, as these represent the highest risk of infection..$^{49}$ Cunha et al. found no additional protector effect when applying revaccination with BCG, but they did report that a longer follow-up time may well reveal the benefits of the second dose..$^{50}$

\section{TREATMENT}

The Brazilian Health Ministry recommends a multidrug therapy regimen for the treatment of children according to age and the subdivision of those cases in paucibacillary and multibacillary forms, according to that observed in tables 1 and $2 .^{21}$

The doses should be preferentially calculated according to the weight of the child: dapsone $1.5 \mathrm{mg} /$ $\mathrm{kg} /$ day, rifampicin $10 \mathrm{mg} / \mathrm{kg} /$ day, and clofazimine 1 $\mathrm{mg} / \mathrm{kg} /$ day. ${ }^{21}$

The Brazilian Health Ministry provides the blister for paucibacillary and multibacillary treatment with capsules of rifampicin (15 mg) and clofazimine (50 mg), and tablets of dapsone $(50 \mathrm{mg})$. The intake of medication in the form of tablets and capsules can be difficult for children, and it is impossible to chew the capsules, which can subsequently lead to an inappropriate dose. The lack of medicines made for children

TABLE 1: Multidrug therapy regimen treatment of paucibacillary leprosy

\begin{tabular}{llll}
\hline Age in years & Daily Dapsone $(\mathrm{mg})$ & Supervised Dapsone $(\mathrm{mg})$ & Supervised Rifampicin $(\mathrm{mg})$ \\
\hline $0-5$ & 25 & 25 & $150-300$ \\
$6-14$ & $50-100$ & $50-100$ & $300-450$ \\
\hline
\end{tabular}

* Adapted from the Guidelines for the Control of Leprosy. Brazilian Ministry of Health, 2002.

TABLE 2: Multidrug therapy regimen treatment of multibacillary leprosy

\begin{tabular}{llllll}
\hline Age in years & $\begin{array}{l}\text { Daily } \\
\text { Dapsone }(\mathrm{mg})\end{array}$ & $\begin{array}{l}\text { Supervised } \\
\text { Dapsone }(\mathrm{mg})\end{array}$ & $\begin{array}{l}\text { Supervised } \\
\text { Rifampicin }(\mathrm{mg})\end{array}$ & $\begin{array}{l}\text { Weekly } \\
\text { Clofazimine }(\mathrm{mg})\end{array}$ & $\begin{array}{l}\text { Supervised } \\
\text { Clofazimine }(\mathrm{mg})\end{array}$ \\
\hline $0-5$ & 25 & 25 & $150-300$ & 100 & 100 \\
$6-14$ & $50-100$ & $50-100$ & $300-450$ & 150 & $150-200$ \\
\hline
\end{tabular}

* Adapted from the Guidelines for the Control of Leprosy. Brazilian Ministry of Health, 2002 
in the form of oral solutions is a limiting factor of the treatment. A similar problem was also reported in the treatment of tuberculosis in this age group. ${ }^{51}$

Generally, case reports on adverse reactions to a multidrug therapy regimen in the treatment of leprosy do not mention the age of the patients affected by these reactions. In international medical literature, only a few cases report on severe side effects that harm children under 15 years of age. However, Kaluarachchi et al. studied hepatic and hematological reactions caused by the use of multidrug therapy regimen for leprosy, through a retrospective study conducted between 1991 and 1995 in Sri Lanka. Of the total of 3,333 new cases of leprosy found, 81 (2.4\% of the patients) with anemia (mainly hemolytic), jaundice with toxic hepatitis or methemoglobinemia, with 14 cases in children under 15 years of age, but discarded the age as a risk factor for adverse reactions to the multidrug therapy regimen and emphasized the importance of dapsone as the drug that most determines medicinal changes in the regimen. ${ }^{52}$ Singh et al. studied adverse reactions to multidrug therapy regimens in 176 patients treated for leprosy during the period of 2006 to 2008, in a region of India, and found 24 (13.6\%) cases in children under 14 years of age, with dapsone also representing the drug that most determined changes in patients, but they did not specify what reactions were unleashed. These authors reported only one case of a 12-year-old boy that presented severe hematemesis, a severe and rare complication caused by clofazimine..$^{53}$

In cases of severe adverse reactions, an alternative multidrug therapy regimen is recommended, with the substitution of progressive medication. ${ }^{21}$ In adults, the alternative regimens use ofloxacin (quinolone) and minocycline (tetracycline), which are contra-indicated in children under 10 years of age, due to the risk of the early closure of the epiphysis as well as dental and bone alterations, respectively. The treatment of the children in these cases should be analyzed cautiously, due to the few therapeutic options.

Lepra reactions should be treated with oral cor- ticotherapy, especially prednisone at a dose of $1 \mathrm{mg} /$ $\mathrm{kg}$ /day until the clinical condition has been brought under control, with a slow and gradual removal of the medication until its complete suspension. ${ }^{54}$ Sevalsekar et al., upon treating 33 children with lepra reaction, the majority with type 1 lepra reaction, obtained full healing through the use of oral corticotherapy in all cases. ${ }^{10}$

\section{CHEMOPROPHYLAXIS IN HIGH-RISK CONTACTS}

Some researchers have suggested the importance of chemoprophylaxis in high-risk contacts, that is, contacts with multibacillary and seropositive to anti-PGL-I cases, using rifampicin $(600 \mathrm{mg})$ for adults of above $35 \mathrm{~kg}$ of body weight, $450 \mathrm{~kg}$ for children above nine years of age, and adults of up to $35 \mathrm{~kg}$, and 300 $\mathrm{mg}$ for children between five and nine years. ${ }^{15,55}$

In a systematic review of six randomized clinical trials on chemoprophylaxis in contacts with leprosy, Reveiz et al. reported a study with rifampicin (single dose), three studies with dapsone (one dose every two weeks for two years, and one dose twice a week for three years, or one dose a week for two years), and two with acedapsone (one dose every 10 weeks for seven months in both). The meta-analysis showed a reduction in the incidence of leprosy among the contacts with patients, varying from $30 \%$ to $72 \%$, with the use of dapsone, acedapsone, or rifampicin. The authors argue that a minimal reduction in incidence among the contact can significantly affect the incidence in countries like Brazil and India, recommending its use in public health policies. ${ }^{56} \mathrm{It}$ is also important to highlight that the single dose regimen of rifampicin seems to be more appropriate than the use of dapsone for two or three years. In both cases, it is necessary to review the impact of such measures on the resistance of the bacillus, since we have a limited therapeutic arsenal to combat leprosy and there are case reports of the resistance to multidrug therapy regimen drugs. ${ }^{57,58}$

\section{REFERENCES}

1. Talhari S, Neves RG, Penna GO, Oliveira MLW. Dermatologia tropical: Hanseníase. 4. ed. Manaus: Fundação Medicina Tropical; 2006.

2. Opromolla DVA. Noções de hansenologia. Bauru: Centro de Estudos Dr. Reynaldo Quagliato; 2000.

3. World Health Organization. Weekly epidemiological record Relevé épidémiologique hebdomadaire. Weekly epidemiological record . 2012;34:317-28.

4. Barbieri CLA, Marques HHS. Hanseníase em crianças e adolescentes: revisão bibliográfica e situação atual no Brasil. Pediatria (São Paulo). 2009;31:281-90.

5. Chaitra P, Bhat RM. Postelimination status of childhood leprosy: report from a tertiary-care hospital in South India. Biomed Res Int. 2013;2013:328673.
6. Souza VF, Silva RS, Valle CL, Obadia DL, Daxbacher EL. Report of three new leprosy cases in children under fifteen in the municipality of Itaguai, Rio de Janeiro - event alert for epidemiological investigation. An Bras Dermatol. 2011;86:1011-5.

7. Pires CAA, Malcher CMSR, Junior JMCA, Albuquerque TG. Hanseníase em menores de 15 anos: a importância do exame de contato. Rev Paul Pediatr. 2012;30:292-5.

8. Datasus.gov.br [Internet]. Taxa de incidência de hanseníase no Brasil por faixa etária, segundo região, 2012 [acesso 15 abr 2014]. Disponível em: http://tabnet. datasus.gov.br/cgi/tabcgi.exe?idb2012/d0206.def. 
9. Barreto JG, Bisanzio D, Guimarães Lde S, Spencer JS, Vazquez-Prokopec GM, Kitron U, et al. Spatial analysis spotlighting early childhood leprosy transmission in a hyperendemic municipality of the Brazilian Amazon Region. PLoS Negl Trop Dis. 2014;8:e2665

10. Selvasekar A, Geetha J, Nisha K, Manimozhi N, Jesudasan K, Rao PS. Childhood leprosy in an endemic area. Lepr Rev. 1999;70:21-7.

11. Jain S, Reddy RG, Osmani SN, Lockwood DN, Suneetha S. Childhood leprosy in an urban clinic, Hyderabad, India: clinical presentation and the role of household contacts. Lepr Rev. 2002;73:248-53.

12. Kar BR, Job CK. Visible deformity in childhood leprosy - a 10-year study. Int J Lepr Other Mycobact Dis. 2005;73:243-8.

13. Imbiriba EB, Hurtado-Guerrero JC, Garnelo L, Levino A, Cunha Mda G, Pedrosa V. Epidemiological profile of leprosy in children under 15 in Manaus (Nothern Brazil), 1998-2005. Rev Saude Publica. 2008:42:1021-6.

14. Rao AG. Study of leprosy in children. Indian J Lepr. 2009;81:195-7.

15. Sachdeva S, Amin SS, Khan Z, Sharma PK, Bansal S. Childhood leprosy: lest we forget. Trop Doct. 2011;41:163-5.

16. Singal A, Sonthalia S, Pandhi D. Childhood leprosy in a tertiary-care hospital in Delhi, India: a reappraisal in the post-elimination era. Lepr Rev. 2011;82:259-69.

17. Lana FC, Fabri Ada C, Lopes FN, Carvalho AP, Lanza FM. Deformities due to leprosy in children under fifteen years old as an indicator of quality of the leprosy control programme in Brazilian municipalities. J Trop Med. 2013;2013:812793.

18. Santos MJ, Ferrari CK, de Toledo OR, de Moraes EV, David FL. Leprosy among children and adolescents under 15 years-old in a city of Legal Amazon, Brazil. Indian J Lepr. 2012;84:265-9.

19. Brubaker ML, Meyers WM, Bourland J. Leprosy in children one year of age and under. Int J Lepr Other Mycobact Dis. 1985;53:517-23.

20. Hammond PJ, Rao PS. The tragedy of deformity in childhood leprosy. Lepr Rev. 1999:70:217-20.

21. Brasil. Ministério da Saúde. Secretaria de Políticas de Saúde. Departamento de Atenção Básica. Guia para o Controle da hanseníase. Brasília: Ministério da Saúde; 2002. Série A. Normas e Manuais Técnicos; n. 111.

22. Romero-Montoya IM, Beltrán-Alzate JC, Ortiz-Marín DC, Diaz-Diaz A, CardonaCastro N. Leprosy in Colombian children and adolescents. Pediatr Infect Dis J. 2014;33:321-2.

23. van Beers SM, Hatta M, Klatser PR. Patient contact is the major determinat in incident leprosy: implications for future control. Int J Lepr Other Mycobact Dis. 1999;67:119-28.

24. Durães SM, Guedes LS, Cunha MD, Magnanini MM, Oliveira ML. Epidemiologic study of 107 cases of families with leprosy in Duque de Caxias, Rio de Janeiro, Brazil. An Bras Dermatol. 2010;85:339-45

25. Lastória JC, Abreu MA. Leprosy: review of the epidemiological, clinical, and ethiopathogenic aspects - Part 1. An Bras Dermatol. 2014;89:205-18.

26. Mira MT, Alcaiis A, Nguyen VT, Moraes MO, Di Flumeri C, Vu HT, et al. Susceptibility to leprosy is associated with PARK2 and PACRG. Nature. 2004;427:636-40.

27. Zhang FR, Huang W, Chen SM, Sun LD, Liu H, Li Y, et al. Genomewide association study of leprosy. N Engl J Med. 2009;361:2609-18.

28. Rabello Filho FE, Portugal H. Lepra tuberculoide. An Bras Dermatol. 1935;10:71-91.

29. Report of the committee on classification. International Congress of leprosy, Madrid; 1953. Int J Lepr. 1953;21:504-16

30. Ridley DS, Jopling WH. Classification of leprosy according to immunity: a fivegroup system. Int J Lepr Other Mycobact Dis. 1966;34:255-73.

31. Gupta R, Kar HK, Bharadwaj M. Revalidation of various clinical criteria for the classification of leprosy - a clinic-pathological study. Lepr Rev. 2012;83:354-62.

32. Foss NT. Leprosy: clinical, immunological and therapeutical aspects. An Bras Dermatol. 1999;74:113-9.

33. Lastoria J, Barreto JA, Oliveira MLW. Hanseníase. In: Lupi 0, Cunha PR, editores. Rotinas de diagnóstico e tratamento da sociedade brasileira de dermatologia. São Paulo: AC Farmacêutica; 2013. p. 321-8.

34. Fakhouri R, Sotto MN, Manini MI, Margarido LC. Nodular leprosy of childhood and tuberculoid leprosy: a comparative, morphologic, immunopathologic and quantitative study of skin tissue reaction. Int J Lepr Other Mycobact Dis. 2003;71:218-26

35. Jacobson RR, Krahenbuhl JL. Leprosy. Lancet. 1999;353:655-60.

36. Moreira SC, Batos CJ, Tawil L. Epidemiological situation of leprosy in Salvador from 2001 to 2009. An Bras Dermatol. 2014;89:107-17.

37. Grover C, Nanda S, Garg VK, Reddy BS. An epidemiologic study of childhood leprosy from Delhi. Pediatr Dermatol. 2005;22:489-90.

38. Ganapati R, Naik SS, Pandya SS. Childhood leprosy - study of prevalence rates and clinical aspects through surveys in Bombay. Lepr India. 1976;48:645-60.
39. Neder L, Rondon DA, Cury SS, Silva CA. Musculoskeletal manifestations and autoantibodies in children and adolescents with leprosy. J Pediatr (Rio J). 2014;90:457-63.

40. Nery JA, Bernardes Filho F, Quintanilha J, Machado AM, Oliveira Sde S, Sales AM. Understanding the type 1 reactional state for early diagnosis and treatment: a way to avoid disability in leprosy. An Bras Dermatol. 2013;88:787-92.

41. Nery JAC, Sales AM, Illarramendi X, Duppre NC, Jardim MR, Machado AM Contribution to diagnosis and management of reactional: a pratical aproach. An Bras Dermatol. 2006;81:367-75.

42. Teixeira MA, Silveira VM, França ER. Characteristics of leprosy reactions in paucibacillary and multibacillary individuals attended at two reference centers in Recife, Pernambuco. Rev Soc Bras Med Trop. 2010;43:287-92.

43. Ramos JM, Reyes F, Lemma D, Tesfamariam A, Belinchón I, Górgolas M. The burden of leprosy in children and adolescents in rural Southern Ethiopia. Paediatr Int Child Health. 2014;34:24-8.

44. Brasil. Ministério da Saúde. Secretaria de Vigilâncla em Saúde. Departamento de Vigilância Epidemiológica. Guia de procedimentos técnicos: baciloscopia em hanseníase. Brasilia: Editora do Ministério da Saúde; 2010. Série A. Normas e Manuais Técnicos.

45. Kumar B, Rani R, Kaur I. Childhood leprosy in Chandigarh: clinico-histopathological correlation. Int J Lepr Other Mycobact Dis. 2000;68:330-1.

46. Barreto JG, Guimarães Lde S, Leão MR, Ferreira DV, Lima RA, Salgado CG. Anti-PGL-I seroepidemiology in leprosy cases: household contacts and school children from a hyperendemic municipality of the Brazilian Amazon. Lepr Rev. 2011;82:358-70.

47. Barreto JG, Guimarães Lde S, Frade MA, Rosa PS, Salgado CG. High rates of undiagnosed leprosy and subclinical infection amongst school children in the Amazon Region. Mem Inst Oswaldo Cruz. 2012;107:60-7.

48. Lwin K, Sundaresan T, Gyi MM, Bechelli LM, Tamondong C, Garbajosa PG, et al. $B C G$ vaccination of children against leprosy: fourteen-year findings of the trial in Burma. Bull World Health Organ. 1985:63:1069-78.

49. Setia MS, Steinmaus C, Ho CS, Rutherford GW. The role of BCG in prevention of leprosy: a meta-analysis. Lancet Infect Dis. 2006;6:162-70.

50. Cunha SS, Alexander N, Barreto ML, Pereira ES, Dourado I, Maroja Mde F, et al. BCG revaccination does not protect against leprosy in the Brazilian Amazon: a cluster randomised trial. PLoS Negl Trop Dis. 2008;2:e167.

51. Pouplin T, Phuong PN, Toi PV, Nguyen Pouplin J, Farrar J. Isoniazid, pyrazinamide and rifampicin content variation in split fixed-dose combination tablets. PLoS One. 2014;9:e102047.

52. Kaluarachchi SI, Fernandopulle BM, Gunawardane BP. Hepatic and haematological adverse reactions associated with the use of multidrug therapy in leprosy - a five year retrospective study. Indian J Lepr. 2001;73:121-9.

53. Singh H, Nel B, Dey V, Tiwari P, Dulhani N. Adverse effects of multi-drug therapy in leprosy, a two year's experience (2006-2008) in tertiary health care centre in the tribal region of Chhattisgarh state (Bastar, Jagdalpur). Lepr Rev. 2011;82:17-24.

54. Brasil. Ministério da Saúde. Secretaria de Vigilância em Saúde. Departamento de Vigilância Epidemiológica. Orientações para uso: corticoesteróides em hanseníase. Série A. Normas e Manuais Técnicos. Brasília: Editora do Ministério da Saúde, 2010. 54p. Série A. Normas e Manuais Técnicos.

55. Moet FJ, Pahan D, Oskam L, Richardus JH; COLEP Study Group. Effectiveness of single dose rifampicin in preventing leprosy in close contacts of patients with newly diagnosed leprosy: cluster randomized controlled trial. BMJ. 2008;336:761-4.

56. Reveiz L, Buendía JA, Téllez D. Chemoprophylaxis in contacts of patients with leprosy: systematic review and meta-analysis. Rev Panam Salud Publica. 2009:26:341-9.

57. da Silva Rocha A, Cunha Md, Diniz LM, Salgado C, Aires MA, Nery JA, et al. Drug and multidrug resistance among Mycobacterium leprae isolates from brazilian relapsed leprosy patients. J Clin Microbiol. 2012;50:1912-7.

58. Williams DL, Hagino T, Sharma R, Scollard D. Primary multidrug-resistant leprosy, United States. Emerg Infect Dis. 2013;19:179-81.

\section{MAILING ADDRESS: \\ Marcela Bahia Barretto de Oliveira \\ Avenida Marechal Campos, 1468 \\ Nazareth, \\ 29047-100 - Vitória - ES - Brazil \\ E-mail:marcela_barretto@yahoo.com.br}

How to cite this article: Oliveira MBB, Diniz LM. Leprosy among children under 15 years of age: literature review. An Bras Dermatol. 2016;91(2):196-203. 